\title{
Intra abdominal testis- role of laproscopy in search of hidden testis
}

\begin{abstract}
A twelve year old boy was operated for right-sided undescended testis. Failure of urogenital union was found with the right testis and caput epididymidis intra-abdominally situated, and the blind ending vas situated at the iliac vessels. The risk of development of malignancy in an intra-abdominal testis has been calculated to be one in 20 to 46times greater than general population. We describe a case in whom impalpable undescended testes was located in a high position. This case highlights the importance of performing a thorough inspection of the entire abdomen and pelvis if the impalpable testis is not found in an expected location. The finding of a blind-ended vas deferens with epididymal tissue at the internal ring does not exclude an intra-abdominal testis. Management of the non palpable testis is consists of ultrasound, MRI, testicular venography, laproscopy. In our opinion, laparoscopy is the ideal first step in the management of patients with a nonpalpable testis, having a great reliability in locating or confirming absence of an occult testis.
\end{abstract}

Volume 6 Issue 4 - 2017

\author{
Abdulrahman Almaawi, Ramakrishna Prasad \\ D, Zakaullah Waqas \\ Department of Pediatric Surgery, King Abdullah Hospital, Saudi \\ Arabia
}

Correspondence: Abdulrahman Almaawi, Department of Pediatric Surgery, King Abdullah Hospital, Bisha, Saudi Arabia, Po box 60,Bisha, Saudi Arabia, Email almaawi@yahoo.com

Received: February 14, 2017 | Published: March 15, 2017

Keywords: undescended testis, non-palpable testis, laparoscopy, orchidopexy

\section{Case report}

12 Year male child was referred from paediatric endocrinology with a diagnosis of right undescended testes. Clinically the testis could not be felt in the inguinal canal. He is a juvenile diabetic and is under treatment for the same and underwent an MRI scan of abdomen which was reported as absence of right kidney and the testes couldn't be localized. This boy was subjected for diagnostic laparoscopy and the findings were as follows. The right internal ring was closed and a vas deferens was coursed medial to lateral, from the expected origin, terminating at above the internal ring. A gubernaculum was identified emanating from the internal ring coursed proximally towards the right iliac fossa. Our aim was to retrieve tissue for biopsy, to our surprise testes was found at right iliac fossa, far more proximal and separate from the blind ending vas, suspended on a broad vascular pedicle, $1.5 \mathrm{~cm} \times 1.0 \mathrm{~cm}$ in size. Keeping the above findings In view laparoscopic orchiectomy was done and the child had a smooth post operative course. Biopsy has revealed testicular tissue with interstitial fibrosis. The tubules exhibit only sertolicells, occasional leydigcells. There is no evidence of malignancy seen. Closed internal ring with vas deferens coursing medial to lateral, terminating just superior to ring the gubernaculum coursing proximally up the retroperitoneum,terminating at testis.

\section{Intra abdominal testis}

Approximately $20 \%$ of all crypt orchid testes are nonpalpable. Between $50 \%$ and $60 \%$ of these are intra-abdominal, canalicular or "peeping" (just inside the internal inguinal ring). Approximately $20 \%$ of nonpalpable testes are absent, and another $30 \%$ (6\% of the total) is atrophic or rudimentary. Intra-abdominal testes are located in a variety of intra-abdominal positions, the majority less than $2 \mathrm{~cm}$ from the internal ring. However, a testis can be adjacent to the kidney, on the anterior abdominal wall, retro vesical, and in other intra-abdominal positions.

The term VANISHING TESTIS indicates that the testicular vessels and a vas deferens are found on surgical exploration, but a testis is absent. In utero infarction of a normal testis by go nodal vessel torsion after gestational weeks 12 to 14 is hypothesized, Complete urogenital nonunion presenting as complete separation of the epididymis and testicle is a rare condition. The anomaly has an embryologic basis and frequently is associated with an undescended testis. In this case of complete separation of the testis and epididymis found incidentally during laparoscopy for intra abdominal testis. It is important to realize that the epididymis and the testis develop from different embryological structures. At the 9 thweek of gestation the mesonephric tubules which develop into the epididymis and arshall \& Shermeta. ${ }^{1}$

\section{Localization studies}

If a testis is not palpable, radiographic studies are often employed to localize and assess the presence or absence of a testis. The surgical literature regarding vanishing testis emphasizes the importance of identification of vasculature supplying and draining the gonad. This is due to the fact that a testis cannot be present in a location absent from a gonadal vein and because the vein and pampiniform plexus almost always indicate the location of the testis, ${ }^{2}$ regardless of the presence of vas deferens and epididymis. As noted by Turek et al., ${ }^{3}$ the surgeon continues to be responsible for the definitive identification of the spermatic vessels.

Diagnostic laparoscopy has now become the preferred modality in the majority of centers. It has an accuracy of $88-100 \%$ in determining the presence, position, size and structure of the testis in various series ${ }^{4,5}$ Therapeutic procedures like laparoscopic orchiopexy or orchiectomy can also be performed at the same time. The European Association of Urology Guidelines on pediatric urology state that laparoscopy is the only examination that can reliably confirm or exclude non-palpable testes. ${ }^{6,7}$

\section{Discussion}

The expected location of intra abdominal testes is a line joining the renal hilum and the internal inguinal ring. The testes develop near to the kidney on the posterior abdominal wall, arising from the urogenital ridge. Development is regulated by the Y chromosome, with migration of the testes inferiorly during gestation to the inguinal canal along the gubernaculum under the influence of a hormone.

Testicular descent References: - London/UK. ${ }^{7}$ 
Table I Congenital anomalies of the mesonephric ducts in the male*

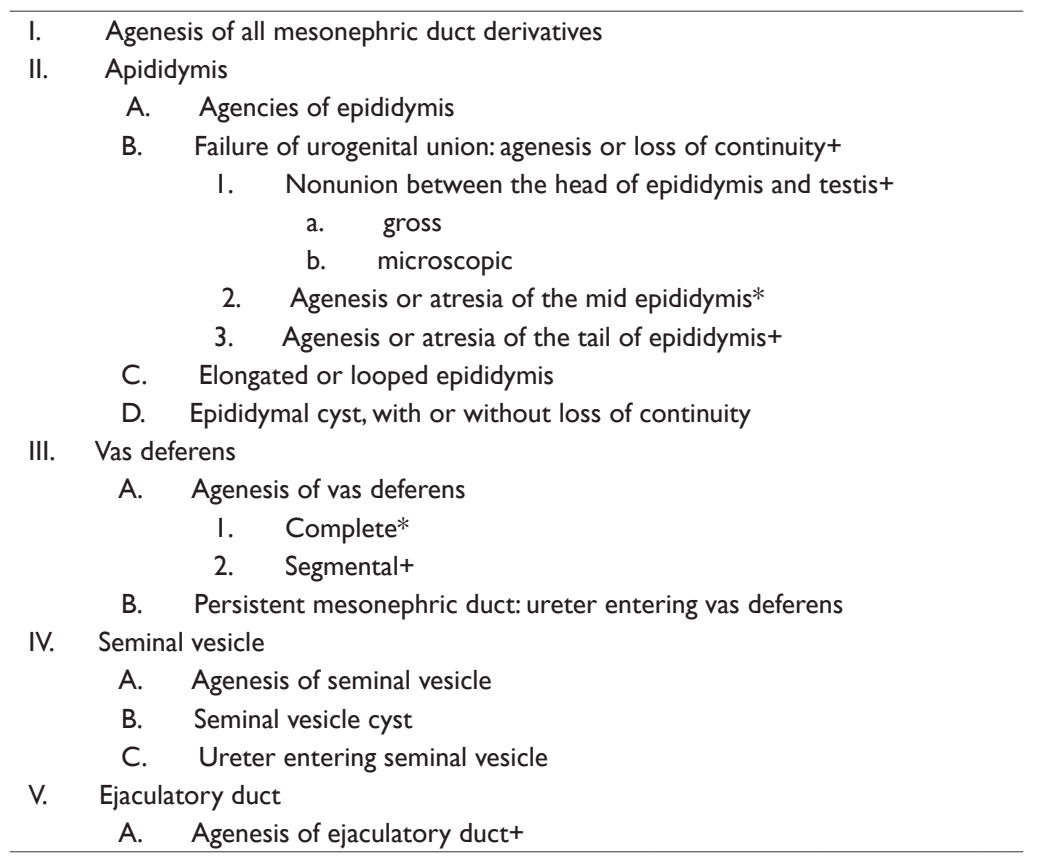

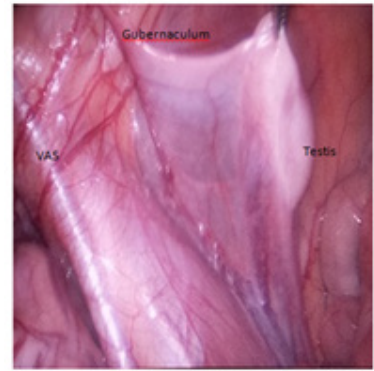

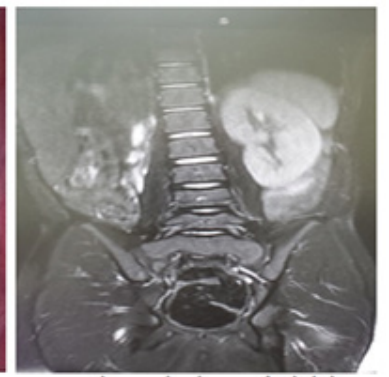

Figure I Closed internal ring with vas deferens coursing medial to lateral,terminating just superior to ring.the gubernaculum coursing proximally up the retroperitoneum,terminating at testis.

Figure 2 Mri showing the absence right kidney.

It appears as though testicle had arrested descent very close to its origin at the renal hilum. This is supported by the fact that the testicular vessels were short with a direct trajectory to and from the IVC and aorta respectively. The inguinal ring was closed and although the vas deferens coursed toward it, it did not enter the ring. Additionally, what appeared to be the gubernaculum coursed from the testicular remnant and traversed the internal ring. This suggests that even though the gubernaculums had an appropriate descent through the internal ring, testis did not descend along the gubernacular path.

In half of the cases reported with complete urogenital nonunion, the testis was found in an intra-abdominal location, whereas the location of the completely separated epididymis and vas deferens included the external ring ${ }^{8}$ distal inguinal canal ${ }^{9}$ inguinal canal ${ }^{10}$ and non mentioned. ${ }^{11}$

Surgery for the nonpalpable testis must determine whether a testicle is present and if one is found, either place it in the scrotum or remove it or declare it absent. The easiest and most accurate way to locate an intra-abdominal testis is by diagnostic laparoscopy, which can be followed by laparoscopic orchiopexy methods to simultaneously achieve therapeutic goals if a testis is found.
The observation of blind-ending spermatic vessels is the sine qua non of a vanishing testis, which is considered to be by prenatal testicular torsion. In such cases, no further exploration is warranted. If a vas deferens and epididymis are seen but blind-ending spermatic vessels are not identified, testicular-epididymal disjunction may be present, and further exploration near the pericolic gutter or the lower of the kidney is required.

An algorithm for surgical management of the impalpable testis based on laparoscopy findings is proposed.

\section{Risk of malignancy}

There is a high risk of malignant transformation in intra abdominal testes .Le Conte first recognized the tumor potential of the undescended testis in $1851 .{ }^{12}$ Since then, the increased risk of malignant degeneration of the crypt orchid testis has been estimated to be 20 to 46 times greater than that of the general population. ${ }^{13}$ Intraabdominal testes are six times more likely to develop a testis tumor than the undescended testis located in an inguinal position. ${ }^{14}$

Theoretically, presence of testicular tissue in testicular remnants indicates a potential for malignancy in the long term. Histopathological examination of testicular remnants in nonpalpable testes demonstrated presence of seminiferous tubules and viable germ cells in 0 to $16 \%$ of the reported series. ${ }^{15-17}$ Based on these observations, some authors suggest routine removal of testicular remnant tissue to prevent malignant transformation, but others did not accept this indication because they could not find testicular tissue in testicular remnants.

Pathologic confirmation of a vanished, regressed testis reassures parents, patients, and surgeons of the correctness of the diagnosis. Interestingly, this testis was not located on MRI but detected at laparoscopy. This is very important in view of development of malignancy in undescended testes when left inside the abdomen

\section{Conclusion}

Laparoscopy for nonpalpable testis is considered to be the most effective technique for diagnosing the presence or absence of the 
testis and the location of the testis especially when ultrasonography and/or MRI are not informative enough. In addition, orchiectomy and orchiopexy can be done as laparoscopically in the patients with intra-abdominal testes. It is suggested that when a blind ending vas is found, it is advisable to follow the spermatic vessels, to look for a hidden testis, the goal should be not leave a vascularized testis intra abdominally, which may lead to malignancy. The finding of a blindended vas deferens at the internal ring does not exclude an intraabdominal testis, should alert the surgeon and follow the gonadal vessels.

\section{Acknowledgments}

None.

\section{Conflicts of interest}

Author declares there are no conflicts of interest.

\section{Funding}

None.

\section{References}

1. Marshall FF, Shetmeta DW. Epididymal abnormalities associated with undescended testis.J.Urol . 1979;121(3):341-343

2. Kirsch AJ, Escala J, Duckett JW, et al. Surgical management of the nonpalpable testis: the Children's Hospital of Philadelphia's experience. JUrol . 1998;159(4):1340-1343.

3. Turek PJ, Ewalt DH, Synder HM III, et al. The absent cryptorchid testis: surgical findings and the implication for diagnosis and etiology. $J$ Urol. 1994;151(3):718-721.

4. Smith NM, Byard RW, Bourne AJ. Testicular regression syndrome-a pathological study of 77 cases. Histopathology. 1991;19(3):269-272.

5. Sutcliffe JR, Wilson-Storey D, Smith NM. Ante-natal testicular torsion: only one cause of the testicular regression syndrome. J R Coll Surg Edinb. 1996;41(2):99-101.
6. Lou CC, Lin JN, Tung TC, et al. Anatomical findings of the vanishing testis. Changgeng Yi Xue Za Zhi. 1994;17(2):121-124.

7. G Price, F Pathiraja, C Allen, et al. m; London/UK The role of MRI in undescended testes ECR 2014 / C-1147.

8. Lythgoe JP. Failure of fusion of the testis and epididymis. $\mathrm{Br} J \mathrm{Urol}$. 1961;33:80-81.

9. Bergdahl L, Andersson A. The importance of a careful search for intraabdominal testes in cryptorchidism. Scand J Urol Nephrol. 1981;15(2):153-155

10. El Gohary MA. Failure of fusion of epididymis and testis: a rarelaparoscopic finding. Eur J Pediatr Surg. 2009;19(2):108-109.

11. Foley PT, Sparnon AL, Lipsett J. Urogenital nonunion-the case for Laparoscopy for the impalpable testis. Pediatr Surg Int. 2005;21(8):655-656.

12. Johnson D, Woodhead DM, PohlDR. Cryptorchidism and testicular tumorigenesi. Surgery. 1968;63:919-922.

13. Campbell HE. Incidence of malignant growth of the undescended testicle. Arch Surg. 1942;44:353-357.

14. Emir H, Ayik B, Elicevik M, et al. Histological evaluation of the testicular nubbins in patients with nonpalpable testis: assessment of etiology and surgical approach. Pediatr Surg Int . 2007;23(1):41-44.

15. Spires SE, Woolums CS, Pulito AR, et al. Testicular regression syndrome: a clinical and pathologic study of 11 cases. Arch Pathol Lab Med. 2000;124(5):694-698.

16. Rozanski TA, Wojno KJ, Bloom DA. The remnant orchiectomy. J Urol 1996;155(2):712-714.

17. Cendron M, Schned AR, Ellsworth PI. Histological evaluation of the testicular nubbin in the vanishing testis syndrome. $J$ Urol . 1998;160(3 pt 2):1161-1162. 